$12-14-2012$

\title{
A Practical Scale for Multi-faceted Organizational Health Climate Assessment
}

\author{
Zandra M. Zweber \\ University of Connecticut, Zandra.Zweber@uconn.edu
}

\section{Recommended Citation}

Zweber, Zandra M., "A Practical Scale for Multi-faceted Organizational Health Climate Assessment" (2012). Master's Theses. 360. https://opencommons.uconn.edu/gs_theses/360

This work is brought to you for free and open access by the University of Connecticut Graduate School at OpenCommons@UConn. It has been accepted for inclusion in Master's Theses by an authorized administrator of OpenCommons@UConn. For more information, please contact opencommons@uconn.edu. 
A Practical Scale for Multi-faceted Organizational Health Climate Assessment

\author{
Zandra M. Zweber
}

B.A., American University, 2010

\author{
A Thesis \\ Submitted in Partial Fulfillment of the \\ Requirements for the Degree of \\ Master of Arts \\ at the \\ University of Connecticut
}

2012 
Master of Arts Thesis

A Practical Scale for Multi-faceted Organizational Health Climate Assessment

Presented by

Zandra M. Zweber, B.A.

Major Advisor

Robert A. Henning

Associate Advisor

Vicki J. Magley

Associate Advisor

Pouran Faghri

University of Connecticut

2012 


\section{ACKNOWLEDGEMENTS}

I would like to extend my sincere appreciation to my advisor, Dr. Robert Henning, and committee members, Dr. Vicki J. Magley and Dr. Pouran Faghri, for their continued insight, guidance, and support. This research would not have been possible without their valued assistance as well as the support from my fellow graduate students. Thank you! 


\section{Table of Contents}

List of Tables.............................................................................

List of Figures .......................................................................... vi

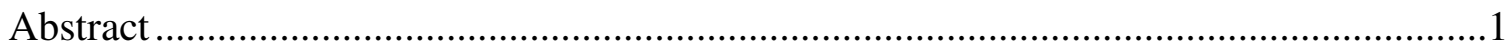

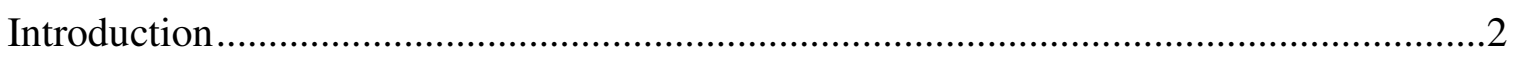

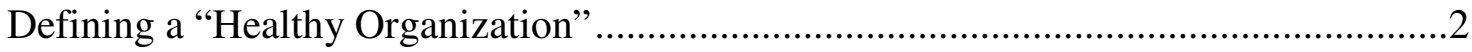

What is Currently Missing from the Definitions of "Healthy Organization" .................4

Health Climate as an Indicator of a Healthy Organization ..........................................5

Previous Conceptualizations of Health Climate.....................................................8

Health Climate and Employee Health ...................................................................

Health Climate vs. Safety Climate ........................................................................12

The proposed Multi-faceted Organizational Health Climate Assessment (MOHCA)...15

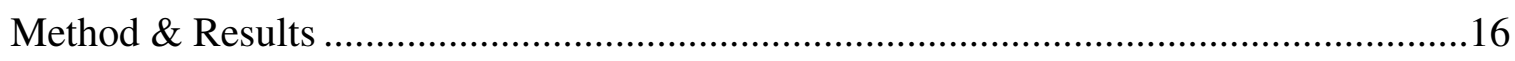

Participants and Procedure .............................................................................. 17

Phase 1: Item Generation of MOHCA...................................................................... 18

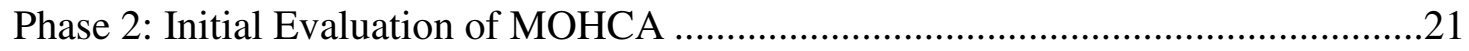

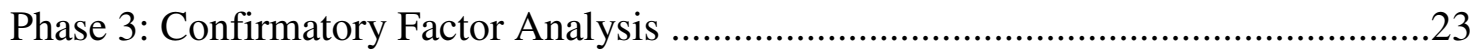

Phase 4: MOHCA Construct Validity Hypothesis Testing ......................................25

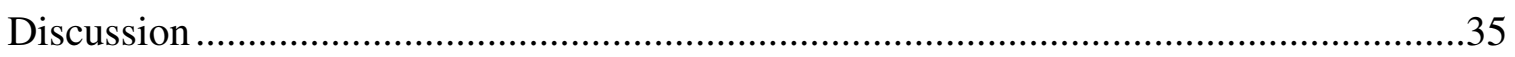

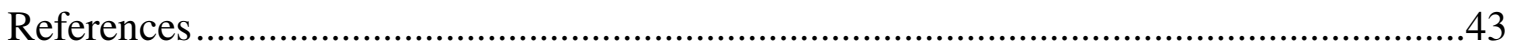

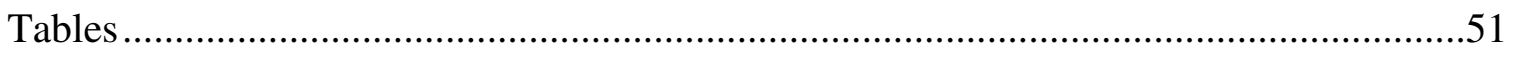

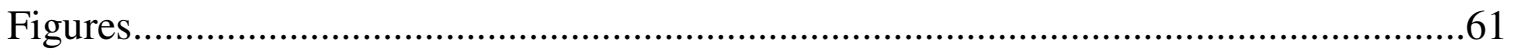




\section{List of Tables}

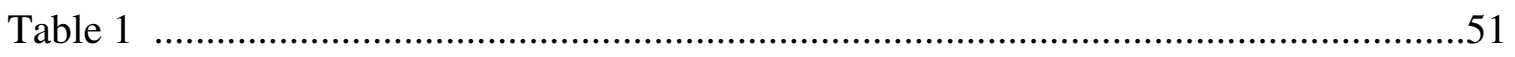

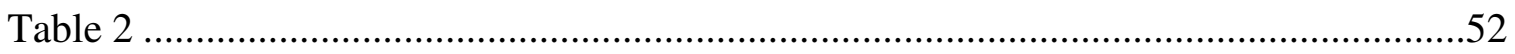

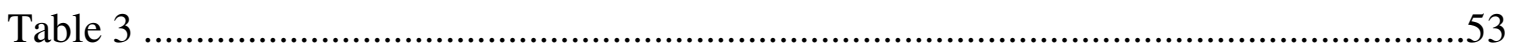

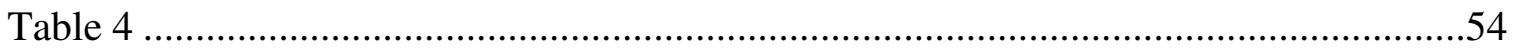

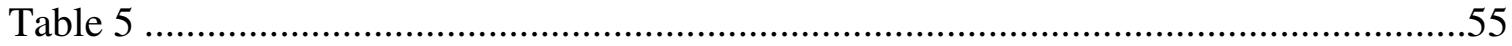

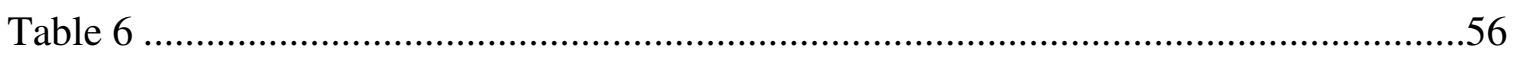

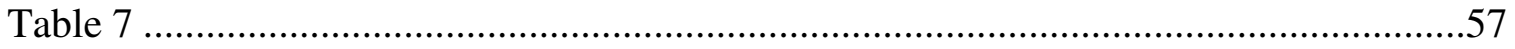

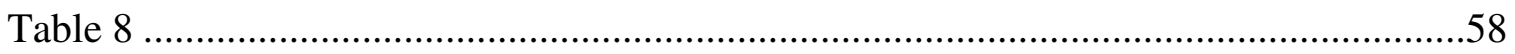

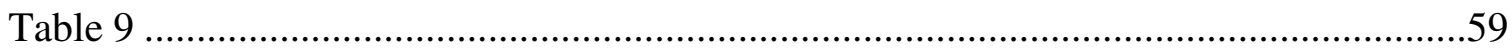

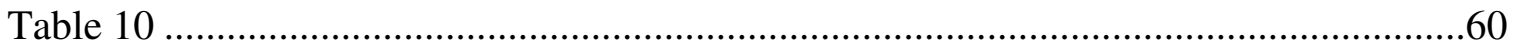




\section{List of Figures}

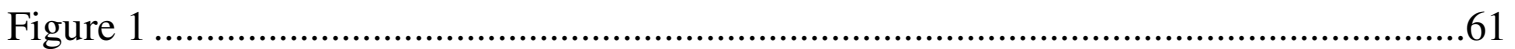




\begin{abstract}
The current study sought to develop a practical scale to measure workplace health climate in a way that has not previously been conceptualized as a three-faceted approach from the employee perspective serving as an indicator of a healthy organization. The goal was to create a short, useable yet comprehensive scale that could translate into practical use by organizations and occupational health professionals planning workplace interventions. To accomplish this, the proposed multi-faceted organizational health climate scale (MOHCA) assesses three-facets which match up with three organizational levels: 1) organization 2) supervisor and 3) workgroup. Ten items were developed and tested on two samples, one cross-organization and one within-organization. After exploratory and confirmatory factor analyses, one item was dropped and a nineitem hierarchical three-factor structure was retained. Validity tests confirmed the MOHCA scale has convergent validity with related constructs, such as perceived organizational support and supervisor support, as well as discriminant validity between MOHCA and safety climate. Lastly, criterion-related validity was found between MOHCA and health-related outcomes. The multi-faceted approach taken in creating the MOHCA scale resulted in a scale that can be easily translated into practice, offering a means for diagnosing the shortcomings of an organization or workgroup's health climate and identifying places for potential health and well-being interventions. Findings from this study also point to the importance of developing workplaces that promote employee health and wellbeing.
\end{abstract}


A Practical Scale for Multi-faceted Organizational Health Climate Assessment

Of growing interest to many researchers and organizations is how to make organizations healthier. Two reasons for this growing interest are the rising health care costs and the many negative outcomes associated with having unhealthy workers. How we define a healthy organization is an important question to answer, first. The current study reviews the multiple definitions of a healthy organization and then shows how a separate, measurable, multi-level "health climate" construct was derived that can be used as one key indicator of a healthy organization.

\section{Defining a "Healthy Organization"}

An examination of the literature indicates a wide range of meanings when researchers use the phrase "healthy organization." Early conceptualizations of a healthy organization had little to do with the actual physical health of the employees who make up the organization, rather they were focused on characteristics of an organization; one that is competitive, innovative, shows growth and is adaptive (Hofmann \& Tetrick, 2003). The definition of organizational health has since evolved to specifically include employee health. For example, a healthy organization has been conceptualized as an organization with a culture that promotes the mental and physical health of employees in addition to productivity and organizational effectiveness (Murphy, 1998). The "well-being of an organization" includes productivity, effectiveness, 
competitiveness and financial health, which researchers argue also impacts individual employee health (Samantary, 2010). Organizational health can also include the extent to which an organization promotes the health of its employees. This is important to note because a shift to defining a healthy organization to also include employee health, rather than depending only on the financial bottom line, would encourage organizations to take a greater interest in the health and well-being of their employees.

As this expansion of organizational priorities has occurred, multiple definitions of a healthy organization have been utilized. Sauter, Murphy $\&$ Hurrell (1990) cite the definition of a healthy organization as one that "maximizes the integration of worker goals for well-being and company objectives for profitability and productivity" (p. 250). Their definition assumes that both the employees and organizational functionality must be considered. In a slightly different interpretation, the American Psychological Association defines a "psychologically healthy organization" in terms of the resources an organization offers its employees such as health promotion programs, employee assistance programs, flexible benefits and working arrangements, health and safety programs, and initiatives for the prevention of work stress (American Psychological Association, 1999). This latter definition is more employee-focused while still seeming to focus on steps the organization takes only when there are employee health issues, as opposed to acting proactively. Kelloway and Day (2005) have extended the definition of a healthy organization to include "the perspective that healthy workplaces are a result not only of the absence of "job 
stressors," but are also the presence of organizational resources that help employees handle job and life stressors" (p. 224). This definition suggests the organization not only respond to employee health issues but also attempts to intervene before health issues are apparent.

Given all of these definitions, it is clear that "healthy organization" has become an umbrella term that covers many domains as a comprehensive construct of both organizational and employee health. A merging of disciplines and specialties such as occupational stress, worksite health promotion, organizational behavior, human resources management and economics is the necessary result of taking an integrative perspective about what a "healthy organization" is (Danna \& Griffin, 1999; Lindstrom, 1994; Sauter, Murphy \& Hurrell, 1990).

\section{What is Currently Missing from the Definitions of "Healthy Organization"}

The differing definitions of a healthy organization described above are an indication of the uncertainty about what it means for an organization to be considered "healthy," and what are the key indicators of a healthy organization. What is still lacking in these definitions is the employee perspective, a psychological dimension that is quite different from the structural and resource dimensions that up until now have been used to define a healthy organization. Employees have some level of awareness of the existence of organizational resources relating to employee health, and these perceptions are known to guide their workplace behaviors and attitudes (Vandenberg, Park, DeJoy, Wilson \& Griffin-Blake, 2002). This is why the employee perspective is so essential to any 
measure of a healthy organization. Although the upper-level managers of an organization might be convinced that they have taken the necessary steps to provide the resources needed to create an environment that supports, maintains or improves employee health and well-being, it is possible that the employees have very different perceptions about this. For example, a new health program to benefit employees would need to align with the perceived needs of employees in order for the program to be perceived as useful and beneficial. If the perceived needs of employees differ from their actual needs, health programs will need to somehow address these needs in order to be fully effective. A discrepancy in real versus perceived needs may suggest the need for interventions to also include an educational effort because employees are not likely to utilize programs that are not aligned with their perceived needs. In general, it is important to assess the extent that the employees value and are satisfied by the organizational practices (Grawitch, Trares \& Kohler, 2007), which is another reason it is useful to consider employee perspectives whenever evaluating a healthy workplace.

\section{Health Climate as an Indicator of a Healthy Organization}

To address the shortcomings identified above, what would be helpful is a measurable construct that is both comprehensive and consistent with the current definitions of a healthy organization, yet also allows organizations and researchers to assess specific aspects of the organization that determine its effectiveness in supporting the health of its employees. This is what has lead to the development of a scale to measure the health climate of an organization. General workplace climate has been defined as the perceptions that people have 
of their work settings (Schneider, 1975). These perceptions can be based on actual or inferred events, as well as practices and procedures that occur in the workplace. Rather than focusing on perceptions of general workplace climate, however, most climate research has targeted specific outcomes by focusing on a more specific dimension or feature of climate such as "climate for support," "climate for creativity" or "safety climate" (Carr, Schmidt, Ford \& DeShon, 2003). Therefore, it could be useful for organizations and researchers interested in studying employee health outcomes in a healthy organization to consider the construct of workplace health climate.

For the purpose of the present study, health climate is defined as:

“Employee perceptions of active support from upper management as well as supervisors and coworkers for the physical and psychological wellbeing of employees."

This conceptualization of health climate encompasses a number of factors such as organizational norms and values, organizational programs, employee attitudes, social support and environmental conditions. By definition, this conceptualization of health climate measures employee perspectives of key dimensions of organizational function in relation to their support of employee health, and can serve as one indicator of the more broad conceptualization of a healthy organization.

This proposed definition of health climate, in contrast to the many ideas about what constitutes a healthy organization, shows potential for a construct that can be measured, validated and tested in regard to its ability to predict 
health and work-related outcomes; for example, the role that health climate plays in the stressor-strain relationship in the workplace can be examined. Although healthy organizations are discussed conceptually, very few studies have sought to empirically test the various models of what healthy work organizations are (Wilson, DeJoy, Vandenberg, Richardson \& McGrath, 2004). This indicates a need for a construct that could be easily measured in order to enable future research studies to focus on empirically examining aspects of healthy work organizations..

From a macroergonomic systems perspective, health climate can be expected to be more than the sum of available resources supporting employee health; it is partly determined by a dynamic interaction among the design factors and people in a complex system. A work system is understood to include things such as social processes (norms, relationships between individuals), resources (physical resources, time, financial), and the organization of resources (how resources are arranged and allocated; Tseng \& Seidman, 2007). These types of systems interactions are likely to influence workplace climates of all types, including health climate. So, while resources may be key components of workplace health climate, there are more advanced ways to approach the measurement of health climate that are more scientifically sophisticated.

In order to develop an accurate way to measure workplace health climate from a systems perspective, it is important to first consider what key functionalities of the system determine this type of climate. As an example of functions of the workplace system that relate to employee health, in their review 
of the literature on healthy workplaces Kelloway and Day (2005) identified safety of work environment, work-life balance, culture of support, respect and fairness, employee involvement and development, work content and characteristics, and interpersonal relationships at work as all contributing to a healthy workplace. Health climate shares the same underlying conceptualization, and therefore the components of health climate can be expected to be similar. Dimensions of workplace climate such as perceived supervisor support, perceived control over work matters, and "worktime flexibility to allow time for personal health needs" are all known to contribute to employee participation in health promotion programs (Basen-Engquist, Hudmon, Tripp \& Chamberlain, 1998) and are consistent with the macroergonomic concept of well-designed humanorganizational interfaces (Hendrick, 2002). These same aspects of the workplace are very likely to contribute to health climate, and therefore deserve to be considered in developing a health climate measure.

\section{Previous Conceptualizations of Health Climate}

The idea of health climate has been touched upon in the literature before, yet previous conceptualizations of health climate have fallen short of igniting much further research in the area. This could be explained by the low reliability of the previously developed scales, their impractical length, or the inadequate definition of the health climate concept itself. The lack of continued research could also be the result of the changing definitions of a healthy organization. Given the shift that has occurred in the construct of organizational health, it is 
important to reconsider measurements associated with this modernized construct such as health climate.

Initially, Ribisl and Reischl (1993) developed the Worksite Health Climate Scale (WHCS). The WHCS ultimately consisted of 62 items broken into 12 specific subscales such as nutrition norms, smoking norms, job tension norms, job flexibility to exercise and supervisor social support. The reliabilities for these subscales ranged from 0.61-0.95. The main problem with the WHCS is that in its full version, using all the subscales together, it is too lengthy to be useful when organizations and researchers need to conduct many other assessments at the same time. One could argue that the WHCS can be broken into its subscales to avoid using the full-length scale. However, if only one or even several of the subscales are used, then general health climate is not really being assessed because each of the twelve subscales has limited scope. For example, measuring just "supervisor social support" doesn't explain much about overall health climate because this is only one dimension of the workplace system. Consistent with the macroergonomic systems perspective that was previously discussed, health climate can be expected to depend instead on the interactions between an individual and multiple key aspects of their environment, including socialorganizational design factors. To be too specific in the items and subscales could limit the ability to assess more important system functions. The proposed health climate scale in this study balances these tradeoffs by having fewer items, yet remaining comprehensive in scope. 
After the WHCS, another health climate scale was developed by BasenEnquist and colleagues (1998). This scale was developed with the purpose of measuring both health climate and safety climate. The health dimension of this scale consists of five items and has a reliability of .74 , so while the number of items is much more practical, its reliability is not very promising. Additionally, an issue with this scale is that the authors failed to adequately define workplace health climate before they sought a way to measure it. Instead, the authors concentrated on what aspects of general climate have been associated with employee participation in health promotion programs. This might indicate the authors' focus on predictive validity rather than construct validity in the construction of this scale. For this reason, although this scale represents a noble attempt at measuring norms and factors surrounding employee participation in health promotion programs in the workplace, it falls short of being a comprehensive measure of workplace health climate when considering the workplace system overall. This obvious shortcoming demonstrates why it is essential to first have a clear and complete definition of health climate before creating items to measure the construct.

\section{Health Climate and Employee Health}

Health climate and healthy organizations have both been associated with many job and health-related outcomes. Previous conceptualizations of health climate, although not fully or precisely defined, have nonetheless been associated with healthier behaviors in employees such as good exercise habits, nutrition habits and smoking status (Basen-Engquist et. al, 1998). Wilson and colleagues 
(2004) found that aspects of organizational climate such as organizational support, coworker support, participation with others and supervisors, communication, and safety and health climate were related to increased job satisfaction, increased organizational commitment, increased efficacy, decreased job stress, and increased psychological health-- including decreased depressive symptoms. Similarly, in their review, Kelloway and Day (2005) found that healthy workplaces resulted in individual outcomes consisting of psychological, physiological and behavioral outcomes; organizational outcomes such as turnover, performance, reputation, customer satisfaction and the bottom line; and societal outcomes such as reduced national health care costs and the existence of government programs.

An important question to keep in mind is why should organizations care about their health climate? Given the research that has documented antecedents and outcomes of healthy organizations, it is reasonable to assume that many of these antecedents and outcomes will be associated with health climate. Therefore, health climate can be expected to be positively associated with employee performance, job satisfaction and employee health, and also be expected to be negatively associated with turnover intentions, job stress, and burnout. Health climate, as defined for this study, impacts not only physical health but also mental health. Therefore in addition to focusing on the absenteeism and lost productivity that is associated with poor physical health in employees (Goetzel, Hawkins, Ozminkowski \& Wang, 2003), organizations need to also focus on the cost associated with poor mental health in their employees. 
Occupational stress is estimated to cost $\$ 100$ billion annually to businesses in the United States, and this is thought of as a conservative estimate (Landsbergis \& Vivona-Vaughan, 1995). In fact, there is evidence of growing interest among organizations to develop interventions and programs to promote or maintain the physical and mental health of their employees given the great cost associated with job stress (Grawitch et. al, 2007). This trend points to the need for developing a more inclusive measure of health climate.

Examining health climate from a social exchange theory framework (Blau, 1964) suggests that if an employee perceives a quality relationship between the organization and its employees, in terms of the organization valuing the employee's well-being, then this employee is more likely to behave in ways that benefit his/her organization. This framework may be relevant because it has been suggested that different types of culture create different forms of psychological contracts between the employer and employee (Vandenberg et. al., 2002). Workers are known to form distinguishable social exchange relationships with their supervisor, coworkers, and organization (Cropanzano \& Mitchell, 2005), suggesting that each one of these can be seen as a potential exchange relationship that has a unique impact on employee health. This focus on the quality of social-relational exchanges is also consistent with macroergonomics principles of feedback control and tracking within an organization. Social Exchange theory has already been applied to the safety climate literature where it was found that employees who work in an environment where safety is a concern reciprocate by complying with safety procedures (Hofmann \& Morgeson, 
1999). Although health climate and safety climate are distinct constructs, this relational exchange framework provides some insight into ways that employees' relationships with supervisors, coworkers and the organization might also lead to increased employee health.

\section{Health Climate vs. Safety Climate}

In addition to the previous definitions not being clear, and evidence that existing measurements of health climate are not reliable nor comprehensive, previous conceptualizations of health climate have arguably been misclassified in the literature. This has perhaps contributed to the subsequent lack of research surrounding health climate. Health climate is often addressed in the safety climate literature because organizational health and safety are often assessed as one construct (Basen-Engquist et. al, 1998; Bjerkan, 2010; Wilson et. al, 2004). Although health and safety are indeed related, it is argued in the present study that they are distinct constructs that also do not share the same relationships with outcomes. Safety is a very specific concept (Bjerkan, 2010) and therefore can mean something completely different than health. This suggests that both organizations and employees could potentially view and prioritize safety and health quite differently.

Safety climate is a construct that continues to be studied extensively in the literature. It is a construct that is comprised of perceptions of safety-related policies, procedures and rewards and the extent to which employees believe that safety is valued within their organization (Griffin \& Neal, 2000). Safety climate has been found to predict individual accidents and injuries in the workplace as 
well as predict accident involvement (Clarke, 2006). There is also evidence that safety climate is related to safety-related behaviors and safety participation (Neal, Griffin, \& Hart, 2000). Because injuries are often studied as an outcome of safety climate, employee health is naturally considered as a related construct to safety. Safety climate is primarily focused on the support and workgroup norms centered around safe practices and behaviors while at work in order to prevent injuries. In contrast, workplace health climate appears to be a distinct construct that goes beyond preventing injury and promoting safe behaviors at work. Health climate is more indicative of the support for employee health, both inside and outside of work. By this definition the proposed health climate construct would be evidenced by things such as workgroup norms, resources put forth from the organization, and communication about employee health and well-being generally as a priority within the organization.

If health climate and safety climate are in fact two distinct constructs, it would actually be problematic to combine them in the same measure. For example, in her measurement of health and safety climate Bjerkan (2010) has an item "I would rather not discuss health and safety environment with my supervisor" (p. 456). If health and safety have different meanings, an employee would have conflicting ways of responding to this item. He or she might feel comfortable discussing safety with their supervisor but not personal health issues. Similarly, in their model of a healthy organization, Wilson and colleagues (2004) used a measure of health and safety climate which had an example item of "there are no significant shortcuts taken when safety and health are at stake" (p. 
571). Safety is a concept that is often associated with legal liability whereas an organization caring about employee health (other than health associated with being safe) can be considered a proactive approach. For this reason, when a single item is used to assess both of these constructs, it is considered "double barreled" and scientifically deficient. It could be the case that an organization does not take shortcuts when it comes to safety but does when it comes to taking proactive steps to ensure long-term employee health. Given that health climate has generally been assessed in combination with safety climate, it has arguably been misclassified. Therefore, research would benefit from a separate classification and proper development of a more comprehensive yet precise measure of health climate.

Although health climate and safety climate are distinct constructs, they share some of the same organizational features. Among the factors identified as components of safety climate are management values, management and organizational practices, communication, and employee involvement in workplace health and safety (Neal, Griffin \& Hart, 2000). This is similar to the organization, supervisor and employee components of health climate which are emphasized in the present multi-faceted approach. In order to justify the need for a new, separate construct of health climate, it must be shown to have some discriminant validity with other measures. If health climate is a fundamentally distinct construct from safety climate then it should also not have high multicolinearity with safety climate. This would also hold true for distinguishing health climate from related constructs such as perceived organizational support, 
perceived supervisor support or civility climate. This does not mean that these constructs cannot be closely related, but a correlation less than .8 would indicate that the multi-faceted health climate is measuring something distinct from these related constructs.

\section{The Proposed Multi-faceted Organizational Health Climate Assessment} (MOHCA)

The Multi-faceted Organizational Health Climate Assessment (MOHCA) is a survey tool designed to measure the climate for health from the perspective of the employee. As mentioned previously, in this study health climate has been defined as employees' perceptions of active support from management as well as supervisors, and coworkers for the physical and psychological well-being of employees. This encompasses factors such as organizational norms and values, employee attitudes, social support and the extent of control over environmental conditions. Keeping this definition in mind, the overall goal was to create a short, useable yet comprehensive, scale that could translate into practical use by an organization when making workplace assessments and planning interventions.

Despite the gap in the literature indicating the need for a practical measure of organizational health climate distinct from safety climate, and which can be used as an indicator of a healthy organization, some related measures do exist within the nomological network of health climate. As previously discussed, support can be considered a key component of the workplace system that determines health climate. There are several measures designed to assess perceptions of different types of support in the workplace such as organizational 
support, supervisor support and workgroup cohesion (Eisenberger, Huntington, Hutchinson \& Sowa, 1986; Eisenberger, Stinglhamber, Vandenberghe, Sucharski \& Rhoades, 2002). However, these types of support are considered general overall support while health climate is more specific to support for health in the workplace.

Additionally, workplace civility norms also fall within the nomological net of health climate. Civility climate is defined as "employee perceptions of the norms supporting respectful treatment among workgroup members" (Walsh, Megley, Reeves, Davies-Schrils, Marmet \& Gallus, in press). In a healthy workplace climate, employees would be respectful of each other's health which is why these two constructs are related, yet health climate involves a more specific type of respect than civility climate. Similarly, citizenship behaviors towards other employees are comprised of things such as taking a personal interest in other employees (Williams \& Anderson, 1991), which is why citizenship is expected to be a related construct to health climate. However, as with civility norms, "citizenship behaviors towards other employees" is a construct that is more general while health climate is more specific to treatment of other employees related to health. Also, as previously outlined in some detail, safety climate is part of the nomological net of health climate in that they are related but distinct constructs. In a similar sense, affective commitment, which is characterized by people remaining with an organization because they want to (Meyer, Allen \& Smith, 1993), should also be a related yet distinct construct from organizational health climate. 
The above examples from the literature show that the development and validation of a measure to assess workplace health climate is needed as a more specific construct that can function as a predictor of employee health outcomes as well as an employee's work attitudes. Hinkin's (1998) guidelines for scale development were used in developing MOHCA, and the validation was laid out over four phases across multiple samples. These four phases are: item generation, initial evaluation (exploratory factor analysis), confirmatory factor analysis and validation.

\section{Method \& Results}

\section{Participants and Procedure}

Sample 1 (Cross-Organization): Sample 1 was comprised of 531 full-time working adults who were recruited using a snowball sampling technique. Using this method participants were recruited by undergraduate psychology students who received partial course credit for recruiting working adults to take the

survey. For this sample, students from three different universities were used to recruit study participants. One of the groups of students who recruited individuals to complete the study came from a large university in the Northeast United States, and two of the groups of students came from two other universities in the Midwest United States. The mean age of the sample was 42 years old. Although one of the Midwestern universities did not collect data on participant sex, of the individuals who reported it, the sample was $55 \%$ female. Sample characteristics can be seen in Table 1. 
Sample 2 (Within-Organization): Health Care employees from a northeast state correctional department were asked to take an online survey as part of a large project with this organization targeting workplace civility. Two hundred and fifty of the 796 ( $31 \%$ response rate) full-time employees completed the survey items needed for this study. The sample was approximately $70 \%$ female, which is not out of the ordinary for health care workers, and the largest age group was 43-51 years old. Because this sample was a within-organization sample, it was possible to collect data on which people worked closely with each other.

Therefore with Sample 2 there was an opportunity to assess health climate at the workgroup level.

\section{Phase 1: Item Generation of MOHCA}

Many items were generated and revised based on feedback from subject matter experts. Items were chosen based on clarity and face validity as well as based on the extent to which they measured different aspects of health climate. This resulted in 10 initial items to be tested. Before constructing the initial items to be tested as part of the proposed MOHCA, time was spent carefully defining the construct of health climate, as described above. After clarifying the definition of workplace health climate, it became clear that there are many aspects that belong in a scale for "healthy workplace climate." The scale was developed to measure three primary interfaces between employees and their work organization, or facets that also match up with organizational levels: employee/workgroup, supervisor, and organizational. Each one of the facets was included because of research discoveries on how workplace climates are 
cultivated. In their discussion of the etiology of workplace climates, Schneider and Reichers (1983) point to interactions between individuals as one of the ways that climates are known to emerge in the workplace. This suggests that health climate is partially influenced by the ways that immediate coworkers interact with each other pertaining to healthy behaviors. Perhaps employees talk to each other about health and support each other when there are health issues, or it is possible that coworkers regularly interact with each other when engaging in unhealthy behaviors (i.e. the major opportunity to socialize with coworkers is during smoke breaks). Employees identify more closely with proximal relationships such as with coworkers than with distal relationship such as the organization (Larkin \& Larkin, 1996). Therefore these interactions between individuals who work closely with each other are likely to impact the way health is viewed by employees at the workgroup level.

With the definition of workplace health climate used here, however, the construct consists of more than just employee interactions. In addition to interactions between individuals, one theory of how climates emerge in the workplace is the structural approach which assumes a large influence of the structure of the workplace (Schneider \& Reichers, 1983). This theory suggests that objective aspects of the workplace such as centrality of decision making, rules and policies, influence the climate. Therefore, rules, policies and decisions around employee health in the workplace would have an impact on employee perceptions of workplace health climate. For this reason, items were included in the MOHCA scale that assessed the contribution of the organization to work 
place health climate. These items address objective aspects of the workplace such as whether the organization provides individuals with the resources to be healthy, the extent of communication between the organization and employees about health, and how well the organization responds to health issues that may arise.

In addition to assessing the workgroup and organizational dimensions of workplace health climate, items were also included in the scale to assess the contributions of the immediate supervisor. This level was assessed because workplace climates can emerge out of a combination of individual interactions with others at work as well as objective policies (Schneider \& Reichers, 1983). In other words, supervisors can have an influence on health climate of a workgroup by not only creating rules, setting performance expectations and facilitating employee input on decision making, they can also influence the health climate by their encouragement of health behaviors within the workgroup and beyond the workplace. For example, the organization may provide a health promotion program at the workplace but a supervisor either may or may not encourage the employees he/she supervises to participate in that program.

Taken together, the items in the MOHCA cover three facets: workgroup, supervisor, and organization. Three items were developed for each of the workgroup and supervisor facets, and four items were developed for the organization facet resulting in an initial scale consisting of ten items. This number of items allows ample flexibility to adequately measure a construct (Hinkin, 1998). Limiting the initial scale to only ten items was also a goal to 
facilitate practical use. Ten items is short enough to be useful for both organizations and researchers while still allowing enough items to maintain sound psychometric characteristics and to measure enough of what we needs to be captured for a meaningful construct of health climate. The scale is scored on a 7-point Likert scale ranging from " 1 " (strongly disagree) to " 7 "(strongly agree). Two of the initial items in the scale are reverse scored because they were negatively worded. The remaining eight items are positively worded. A higher score on the overall health climate scale indicates a better workplace health climate.

In addition to carefully defining health climate to then develop a set of items to assess these three facets, consideration was given to the written directions for employees that would accompany the scale during survey administration. This is because many of the items include the terms "health" and "well-being" which can have multiple meanings. To an extent, their specific meaning is not critical in the sense that it is more important how an individual personally defines "health" and "well-being" in combination. If an individual feels being at work benefits his/her health and well-being then that is meaningful in the context of health climate. It was decided that it was necessary to first provide a definition of health and well-being to survey participants to convey that what is being assessed is more than just physical health, to make sure that the mental aspect of health would be considered when thinking about health climate. The set of directions included on the scale reads: 
When the following items refer to 'health and well-being', this covers your physical, mental and emotional health, and their impact on your ability to work and enjoy life.

This set of directions also reminds the participant that health also has impacts beyond the workplace. National efforts such as the Center for Disease Control's (CDC) Total Worker Health ${ }^{\mathrm{TM}}$ Program have supported this idea of health both at work and outside of work. The CDC states "the protection, preservation, and improvement of the health and well-being of all people who work are goals shared by workers, their families, and employers" (CDC, n.d.).

\section{Phase 2: Initial Evaluation of MOHCA}

After developing the initial ten items based on the existing definition and associations with a healthy organization, and with our working definition of health climate, the next step was to examine the factor structure of the initial workplace health climate scale. Data on the initial ten-item scale were collected from two samples, Sample 1 cross-organization and Sample 2 withinorganization. The initial factor structure was examined using exploratory factor analysis on a split half of the data from Sample 1 (Sample la). This factor structure was confirmed by a confirmatory factor analysis performed on the other split half of Sample 1 (Sample 1b) as well as on Sample 2. The purpose of Phase 2 in the evaluation of MOHCA was to examine the initial psychometric properties and initial factor structure of MOHCA.

Results of Phase 2 
First, scale interitem correlations were completed on both Sample 1 and Sample 2. Table 2 presents the correlations among items in Sample 1 and Sample 2. Item 1 was correlated less than .40 with each of the other items and therefore this item was eliminated (Kim \& Mueller, 1978).

Principal components analysis was then conducted on a random split half of Sample 1 (Sample la) on the nine remaining items to determine the initial structure of these items (Tabachnick \& Fidell, 1989). Sample characteristics can be seen for Sample la in Table 1. Using this analysis, to ascertain the number of factors to retain, the two criteria that were used were the scree plot (Cattell, 1966) and Kaiser criterion (eigenvalues greater than 1.0; Kaiser, 1960). Results from the scree plot (see Figure 1) clearly indicate a one-factor solution. Drawing the conclusion of a one-factor solution was also evidenced by the Kaiser criterion. There was one eigenvalue larger than 1.0 (5.47) and while the next highest eigenvalue was 1.00, a second factor only had one item load on it. Therefore, a single factor was identified which accounted for $60.75 \%$ of the variance, which is above the desired level of $60 \%$ (Hinkin, 1998). Given that the percent variance accounted for was above the desired level, no other items were dropped at this stage. Communalities and factor loadings were examined to support this decision. Factor loadings for the 9-item one-factor solution can be seen in Table 3. Coefficient alpha for the 9-item MOHCA in Sample la was $\square=$ .91.

Additionally, in the initial evaluation stage the intraclass correlation (ICC) of MOCHA was assessed on Sample 2. An ICC could not be calculated for Sample 
la or Sample 1b because these were cross-organizational samples where workgroup data was not collected. The ICC for the MOHCA in Sample 2 was .33 indicating good reason for this scale to be used at a workgroup level.

\section{Phase 3: Confirmatory Factor Analysis}

Following the exploratory factor analyses, confirmatory factor analyses were tested on the 9-item MOHCA in the second random split half of Sample 1 (Sample 1b) and Sample 2. These two samples were chosen because Sample 1 represents a cross-organization sample and Sample 2 represents a withinorganization sample. Confirmatory factor analyses were conducted on these two samples independently.

Results of Phase 3

Descriptives and characteristics of Samples $1 \mathrm{~b}$ and 2 can be seen in Table 1. A hierarchical three-factor model was also tested in both samples for model comparison to ensure the one-factor solution, as found in the exploratory factor analysis, was the best fit to the data. A three-factor hierarchical confirmatory factor analysis was chosen as a comparison to the one factor model because it was theoretically assumed that there would be one factor for each of the three facets (workgroup, supervisor and organization) and that these three facets would all contribute to one latent construct of health climate. The hierarchical three-factor solution was tested and yielded a better model fit than the onefactor solution in each of the two samples (Chi square difference test: Sample lb $\square^{2}=34.2, \mathrm{df}=1, p<.01 ;$ Sample $\left.2 \square^{2}=19.91, \mathrm{df}=1, \mathrm{p}<.01\right)$, and therefore the 
higher-order three-factor model was retained. The disturbance terms of the three first-order factors were set to be equal to each other in the higher-order threefactor model. This was done because theoretically and empirically the three factors are highly correlated with each other and therefore it is reasonable to predict that the higher-order factor would account for the same amount of variance in each of these lower-order factors, yielding the same amount of variance not accounted for (the disturbance).

AMOS 7.0 (Arbuckle, 2006) was used to validate the higher-order threefactor structure of the MOHCA through confirmatory factor analyses in Sample $1 \mathrm{~b}$ and Sample 2. Given the sensitivity of obtaining a significant $\square^{2}$ with large sample sizes, it has been suggested to report two fit statistics and consider them in combination (Hu \& Bentler, 1999; Kline, 1998). The two supplemental fit indices that were examined in this study were the comparative fit index (CFI; Bentler, 1990) and root mean square error of approximation (RMSEA). The CFI, which estimates the covariation in the data explained by the model, was chosen due to the relative stability of the CFI in sample sizes smaller than $\mathrm{N}=250$ (Hu \& Bentler, 1995). The RMSEA estimates the amount of error of approximation per model degrees of freedom and this takes sample size into account. Although the existence of cutoff points is sometimes challenged (Marsh, Hau \& Wen, 2004), it is recommended that a CFI of .95 or greater and a RMSEA of .10 or less are indicators of good fit (Hu \& Bentler, 1999).

In Sample 1b the higher-order three-factor model demonstrated good fit with a $\square^{2}(26)=88.87, p<.001$, CFI $=.97$ and RMSEA $=.10$ (See Table 5). The 
higher-order three-factor model also demonstrated adequate fit in Sample 2, $\square^{2}$ $(26)=179.85, p<.001, \mathrm{CFI}=.88$ and RMSEA $=.15$ (See Table 4). Jackson, Gillaspy and Pure-Stephenson (2009) also suggest examining the strength of the factor loadings in addition to the fit statistics. The standardized factor loadings from the first-order factors to the items in Sample $1 \mathrm{~b}$ ranged from .68 to .97 and from .39 to .99 in Sample 2 (see Table 3). The standardized factor loadings for the paths leading from the first-order factors (workgroup, supervisor and organization) to the second-order factor (health climate) can be seen in Table 4

\section{Phase 4: MOHCA Construct Validity Hypothesis Testing}

The purpose of Phase 4 was to examine the network of constructs surrounding MOHCA through multiple studies' appraisals of convergent, discriminant, criterion-related and incremental validity. First, when determining which constructs should be used for convergent validity, the definition of workplace health climate and its components were considered. Because a core component of workplace health climate is support from the three dimensions (workgroup, supervisor and organization), the relationships among perceived supervisor support (PSS), perceived organizational support (POS), workgroup cohesion and the entire MOHCA were evaluated in order to assess convergent validity. The difference between these forms of support and workplace health climate is that PSS, POS, and workgroup cohesion are more general while workplace health climate focuses exclusively on support for health. Despite the differences between these constructs, we expect there to be a positive relationship between MOHCA and PSS, POS and workgroup cohesion. 
Hypothesis 1: The MOHCA will be positively associated with (a) Perceived organizational support, (b) perceived supervisor support, and (c) workgroup cohesion.

As discussed previously when explaining the definition and construction of the items for the MOHCA, health climate consists of more that just support. It is more comprehensive in nature in that it also assesses the quality of the interaction between individuals and the organization as a relationship. For this reason in the process of assessing convergent validity, the constructs of citizenship behaviors towards other employees and civility norms were also examined. Citizenship behavior towards other employees involves helping other employees and taking an interest in their well-being (Williams \& Anderson, 1991). Therefore it is expected that citizenship behavior towards other employees would be positively related to the MOHCA scale. Similarly, civility climate is defined as "perceptions of norms supporting respectful treatment among workgroup members" (Walsh, Magley, Reeves, Davies-Schrils, Marmet \& Gallus, in press). Respect for workgroup members can be seen to be related to caring about the well-being of workgroup members, and therefore it is expected that civility norms will be positively associated with MOHCA.

Hypothesis 2: The MOHCA scale will be positively associated with (a) citizenship behaviors towards employees and (b) civility norms. 
In order to validate the MOHCA scale, discriminant validity was also assessed. This was done in a few different ways. First, a major part of arguing for the need of a new conceptualization of workplace health climate is that health climate and safety climate are distinct constructs. It is important to test this using discriminant validity checks to ensure the two constructs are not too closely related. Health climate and safety behaviors are likely to be related constructs because health is an outcome of being safe. When safety behaviors are non existent, then health can be negatively affected when accidents lead to ill health. This, however, is not closely related to perceived climate for health in the workplace. In other words, being in a workplace where safe behaviors are commonplace doesn't necessarily mean that there is a workplace climate for promoting health. Therefore, we hypothesize that the MOHCA scale will be positively related to safe behavior, but this correlation will be significantly lower than the correlation between safety climate and safety behavior.

Hypothesis 3: MOHCA will be positively associated with safety behavior, but this correlation will be significantly lower than the correlation between safety climate and safety behavior.

Additionally, discriminant validity can be examined with the relationship between MOHCA and affective organizational commitment. Affective commitment involves feeling a sense of belonging and being emotionally attached to the organization (Meyer, Allen \& Smith, 1993). This is similar to feeling supported by the organization and by supervisors. It is predicted that 
MOHCA will be related to affective commitment to the organization because positive emotions towards the organization are likely the outcome of an organization that promotes employee health. However, because organizational support is a core aspect of MOHCA, it is expected that MOHCA will be more strongly related to perceived organizational support than to affective organizational commitment. Also, it is hypothesized that perceived organizational support is more strongly related to affective commitment than MOHCA because organizational commitment can be conceived as the psychological attachment felt by an employee towards their organization (O'Reilly \& Chatman, 1986). This commitment to the organization can be expected to be closely related to the organization's commitment to the employee, in other words, as reciprocal to perceived organizational support (Shore \& Wayne, 1993).

Hypothesis 4: MOHCA will be positively associated with affective organizational commitment, but this correlation will be significantly lower than the correlation between workplace health climate and perceived organizational support.

To examine the criterion-related validity of the MOHCA scale, the association of the workplace health climate scale and several health-related constructs was assessed. Specifically, the association between health climate and job stress, burnout, fatigue, and "healthy days" was measured. Within the health climate scale, health and well-being are defined to include physical and mental 
health, and therefore a strong workplace health climate should result in lower levels of job stress in employees. Similarly, a strong workplace health climate should result in lower levels of burnout and fatigue given that burnout is a construct related to mental and physical health because it consists of dimensions of disengagement and exhaustion. Healthy Days is a measure developed by the Centers for Disease Control (CDC) to measure health, and because employee health should be a result of a strong workplace health climate, healthy days should also be positively related to workplace health climate. The incremental contribution of MOHCA to health-related outcomes beyond the effects of perceived organizational support, perceived supervisor support, and workgroup cohesion is also predicted.

Hypothesis 5: MOHCA will be negatively associated with (a) job stress, (b) burnout and (c) fatigue.

Hypothesis 6: MOHCA will be positively associated with healthy days. Hypothesis 7: MOHCA will be negatively associated with (a) job stress, (b) burnout and (c) fatigue and beyond the effects of perceived organizational support, perceived supervisor support and workgroup cohesion. Hypothesis 8: MOHCA will be positively associated with healthy days beyond the effects of perceived supervisor support.

Lastly, the incremental contribution of MOHCA to health-related outcomes is predicted beyond the effects of safety climate in order to support the argument 
that health climate is more comprehensive in terms of employee health than safety climate.

Hypothesis 9: MOHCA will be negatively associated with (a) job stress and positively associated with (b) healthy days beyond the effects of safety climate.

\section{Validation Measures}

Participants from both samples took online surveys (different for each sample) that included the MOCHA. Items were evaluated on scales ranging from "1" (strongly disagree) to "7" (strongly agree) unless otherwise noted. See Tables 5 and 6 for coefficient alpha internal consistency.

Sample 1:

Perceived Supervisor Support was measured using 3 items (Eisenberger, Stinglhamber, Vandenberghe, Sucharski \& Rhoades, 2002). An example item for this scale is "My supervisor takes pride in my accomplishments at work." A previous reliability estimate of this scale was .88 .

Stress in General/Job Stress was measured using 4 items from Stress in General/Job Stress measure (Stanton, Balzer, Smith, Parra \& Ironson, 2001). An example item from this scale is "In general, I think my job is hectic." A previous reliability estimate for this scale was .82 .

Civility Norms were measured using the 4-item Civility Norms Questionnaire- Brief (Walsh, Magley, Reeves, Davies-Schrills, Marmet \& Gallus, 
in press). An example item is "rude behavior is not accepted by your coworkers." A previous reliability of this scale was .81 .

Fatigue was measured using 3 items (Chalder, Berelowitz, Pawlikowska, Watts, Wessely, Wright \& Wallace, 1993). An example item is "During the past six months, have you had problems with tiredness?" A previous reliability of a longer version of this scale was .88 .

Healthy Days was measured using an item from the Center for Disease Control's Healthy Days measure (Moriarty, Zack \& Kobau, 2003). This scale for this item was 0-30 where participants rated, for example, the number of days during the past 30 days when their physical health was not good.

Safety Climate was measured using 3 items of management commitment to safety (Neal \& Griffin, 2006), and 4 items of supervisor support of safety (Hayes, Perander, Smecko, \& Trask, 1998). An example item from management commitment to safety is "safety is given a high priority by management" and an example item from supervisor support to safety is "encourages safe behaviors". These two scales were used as a proxy for safety climate because according Neal and Griffin (2000), management values and management and organizational practices are key components to safety climate.

Safety Behaviors will be assessed using a measure of safety compliance. Safety compliance was measured using 3 items (Neal \& Griffin, 2006). An example item is "I follow correct safety rules and procedures while carrying out my job." 
Workplace Accidents were assessed using 3 items assessing self reported workplace accidents (Smecko \& Hayes, 1999). An example item is "(in the past 6 months) how many minor injuries did you receive at work?"

Sample 2:

Stress in General/Job Stress was measured using the 6 item Stress in General/Job Stress measure (Stanton, Balzer, Smith, Parra \& Ironson, 2001). An example item from this scale is "In general, I think my job is pressured." A previous reliability estimate of this scale was .82 .

Burnout was measured using 4 items from the Oldenburg Burnout Inventory (Demerouti, Bakker, Nachreiner \& Shufeli, 2000). An example item from this scale is "After work, I usually have enough time for leisure activities."

Perceived Organizational Support will be measured using 4 items from Eisenberger, R., Huntington, R., Hutchinson, S., \& Sowa, D. (1986). An example item is "CMHC really cares about my well-being." A previous reliability estimate of this scale was .88.

Civility Norms was measured using 7 items from the Civility Norms Questionnaire- Brief (Walsh, Magley, Davies-Schrills, Marmet, Reeves \& Gallus, 2008). An example item is "respectful treatment is the norm in our work group." A previous reliability estimate of this scale was .81.

Workgroup Cohesion was measured using 4 items. An example item is "we work well together as a team." 
Citizenship Behavior toward other employees was measured with 2 items (Williams \& Anderson, 1991). An example item is "I take personal interest in the well-being of others (e.g., help new employees)." A previous reliability estimate of this scale was .88 .

Affective Organizational Commitment was measured with 3 items (Meyer, Allen \& Smith, 1993). An example item is "I feel a strong sense of 'belonging' to CMHC". A previous reliability estimate of this scale was .87 .

\section{Results of Phase 4}

Hypotheses 1 through 6 were tested via a series of correlations in Sample 1 (whole sample) and Sample 2. The following results present the correlations between the overall 9-item MOHCA scale and variables of interest, however zero-order correlations among all the variables and all factors are presented in Tables 6 and 7. Hypotheses were tested in each sample depending on availability of constructs in that sample. The MOHCA scale was positively correlated with perceived organizational support $(\mathrm{r}=.67, \mathrm{p}<.01)$ and workgroup cohesion $(\mathrm{r}=.45$, $\mathrm{p}<.01$ ) in Sample 2, supporting hypotheses la and lc. MOHCA was also positively correlated to perceived supervisor support $(\mathrm{r}=.58, \mathrm{p}<.01)$ in Sample 1 in support of Hypothesis 1b. Hypothesis 2a was supported in Sample2 with the significant positive correlation between MOHCA and citizenship behaviors towards other employees $(\mathrm{r}=.23, \mathrm{p}<.01)$. Both samples provided support for Hypothesis 2b indicating a strong positive correlation between health climate and civility norms (Sample1: $\mathrm{r}=.52, \mathrm{p}<.01$; Sample 2 : $\mathrm{r}=.58, \mathrm{p}<.01$ ). Support of 
Hypotheses 1 and 2 provides evidence for the convergent validity of the MOHCA scale.

Hypothesis 3 posits that MOHCA will be positively associated with safety behaviors, but that this correlation will be lower than the correlation between safety climate and safety behaviors. Results from Sample 1 indicate that the correlation between MOHCA and safety behaviors $(\mathrm{r}=.29, \mathrm{p}<.01)$ is weaker than the correlation between safety climate and safety behaviors $(\mathrm{r}=.41, \mathrm{p}<.01)$. Similarly, Hypothesis 4 examines the correlations between MOHCA and affective organizational commitment and MOHCA and perceived organizational support. Results from Sample 2 indicate that the correlation between MOHCA and affective organizational commitment $\left(\mathrm{r}=.66^{* *}, \mathrm{p}<.01\right)$ is very similar to the correlation between MOHCA and perceived organizational support $(\mathrm{r}=.69, \mathrm{p}<.01)$ which does not support Hypothesis 4. Although Hypothesis 4 was not supported, support of Hypothesis 3 provides some evidence for discriminant validity with the MOHCA scale.

Hypothesis 5a was supported by results from both samples. Job stress was negatively correlated with MOHCA in Sample $1(\mathrm{r}=-.25, \mathrm{p}<.01)$ and Sample 2 $(\mathrm{r}=-.45, \mathrm{p}<.01)$. Hypothesis $5 \mathrm{~b}$ was tested and supported in Sample 2 with MOHCA being significantly negatively related to burnout $(\mathrm{r}=-.41, \mathrm{p}<.01)$. Hypothesis 5c was tested and supported in Sample 1 with MOHCA being significantly negatively correlated with fatigue $(\mathrm{r}=-.28, \mathrm{p}<.01)$. In Sample 1 Hypothesis 6 was also tested with results indicating that MOHCA was indeed significantly positively related to "healthy days" $(\mathrm{r}=.20, \mathrm{p}<.01)$. 
In order to test Hypotheses 7, 8 and 9, hierarchical regression analyses were performed to examine the incremental contributions of MOHCA to health related outcomes (see tables 8 and 9). In Sample 1, Hypothesis 7a, 7c and 8 were tested separately by first entering perceived supervisor support in Step 1 of the regression and then entering MOHCA in Step 2 with job stress, (7a) fatigue (7c) and healthy days (8) as the dependent variables. Results from Sample 1 for Hypothesis 7a indicate that perceived supervisor support captures a significant amount of variation in job stress (standardized $\square=-.23, p<.001$ ), and MOHCA accounted for an additional $1.9 \%$ of the variance in Step 2 (standardized $\square=-.13$, $p<.05$, total $R^{2}=7.1 \%$ ), thus supporting Hypothesis 7a in Sample 1. Hypothesis 7c was tested in the same way in Sample 1. Results indicate that perceived supervisor support captures a significant amount of the variance in fatigue (standardized $\square=-.17, p<. .001$ ), and MOHCA did account for an additional 5\% of the variance in Step 2 (standardized $\square=-.27, p<.001$, total $R^{2}=8.1 \%$ ), thus Hypothesis 7c was supported. Similarly Hypothesis 8 was tested on Sample 1 using this same method. Results indicate that perceived supervisor support does not capture a significant amount of the variability in healthy days (standardized $\square=.08, p=.17)$, but MOHCA does account for an additional $4.5 \%$ of the variance (standardized $\square=.26, p<.001$, total $R^{2}=4.7 \%$ ), thus Hypothesis 8 was partially supported.

Hypothesis 7a was also tested in Sample 2 along with Hypothesis 7b. These hypotheses were tested separately by first entering perceived organizational support and workgroup cohesion in Step 1 of the regression and 
then entering MOHCA in Step 2 with stress (7a) and burnout (7b) as the dependent variables (see Table 9). Results for Hypotheses 7a and 7b indicate that perceived organizational support and perceived supervisor support accounted for a significant amount of the variation in both stress and burnout. MOHCA accounted for an additional $6.1 \%$ of the variance in stress (standardized $\square=-.36$, $p<.001$ ) and an additional 2.5\% of burnout (standardized $\square=-.23, p<.01$ ), thus Hypotheses 7a and 7b were supported in Sample 2. Collectively, the findings from Hypotheses 5 through 8 indicate that MOHCA has incremental validity and has value as a predictor of health-related outcomes.

Hypothesis 9 was tested in Sample 1 in order to determine the incremental contribution of MOHCA to health outcomes above and beyond safety climate. Hypotheses $9 \mathrm{a}$ and $9 \mathrm{~b}$ were tested separately by first entering safety climate in Step 1 of the regression and then entering MOHCA in Step 2, where job stress and healthy days were the dependent variables (see Table 10). Results for Hypotheses 9a indicate that safety climate captures a significant amount of variance in job stress (standardized $\square=-.22, p<.001$ ), and MOHCA accounted for an additional $1.8 \%$ of the variance in Step 2 (standardized $\square=-.17, p<.05$, total $\left.R^{2}=6 \%\right)$, thus supporting Hypothesis 9a. Hypothesis 9b was tested in the same way in Sample 1. Results indicate that safety climate captures a significant amount of the variance in healthy days (standardized $\square=.10, p<.05$ ), and MOHCA accounted for an additional 4\% of the variance in Step 2 (standardized $\square$ $=.26, p<.001$, total $\left.R^{2}=4.9 \%\right)$, thus Hypothesis $9 \mathrm{~b}$ was also supported. Support 
of Hypothesis 9 suggests that MOHCA has incremental validity over safety climate in predicted health-related outcomes.

\section{Discussion}

The purpose of this study was to develop a practical scale to measure health climate in a way that is consistent with current conceptualizations of a healthy organization. An approach that focuses on three organizational facets was taken when developing survey items in order for the scale to be easily translated into practice. This makes it possible to diagnose any specific shortcomings, and thereby identify areas to target for potential health and wellbeing interventions. What also differentiates this new scale from previous conceptualizations of health climate are its sound psychometric properties, clear definition and classification of health climate, and usability. Additionally, the known etiology of workplace climates was carefully considered when developing items for the MOHCA. This lead to the idea of three organizational facets as contributors to the health climate construct, providing a level of specificity that is a unique contribution of this scale.

The psychometric properties of the Multi-faceted Organizational Health Climate Assessment were assessed across two samples $(\mathrm{N}=781)$. The findings recommend adoption of a nine-item hierarchical three-factor structure that is able to show high internal consistency across samples. The higher-order threefactor structure that was determined in the development of the MOHCA scale allows researchers and practitioners to use the scale to assess the overall latent construct of health climate as well as to assess the three factors of workgroup 
level, supervisor level and organizational level separately. In the original ten items there were two reverse-scored items (items 1 and 4 seen in Table 2). Item 1 was dropped due to very low correlations with the other items and also because its content was determined to be too general and potentially confusing to respondents. Item 4 was retained, however this item also had relatively low correlations with the other items; if Item 4 is removed, the reliability for the factor that it loads on (supervisor health climate) increases significantly in both samples. The poor fit of these two items could likely be due to method bias given they were the only two reverse-scored items. Future users of the MOCHA could consider including these items in a positively worded fashion.

Additionally, it is possible that the two reverse-scored items did not fit well with the other items because the language used in these items may have demanded too much mental effort to consider. This may highlight the need to adapt the wording of items based on the target sample. Adapting items may also be warranted when the structure of an organization varies such that the levels of workgroup, supervisor, and organizational are not meaningful, or when other organizational levels would be more salient. Interestingly, the results in the present study did not differ much between Sample 1 and Sample 2. It was expected that the within-organization sample would have stronger correlations given that it was known to the researchers that the levels of workgroup, supervisor and organizational were salient in this organization. It was also known that the within-organization sample was comprised of individuals with a 
relatively high level of education, suggesting that the reading level or complexity of the items would not be problematic.

Results from the two samples also provide sound evidence for the convergent, discriminant, criterion-related and incremental validity of the 9-item MOHCA. Results from the scale validation efforts also indicated that MOHCA did not have any multicolinearity issues with the other constructs assessed in this study. This finding is important because it provides evidence that MOHCA is a distinct construct. MOHCA was found to have convergent validity with perceived organizational support, perceived supervisor support, workgroup cohesion, civility norms and organizational citizenship behaviors towards other employees. Divergent validity was found in regards to the comparative relationships between MOHCA and safety behaviors and safety climate and safety behaviors. However, divergent validity was not found in regards to the relationship between MOHCA and affective organizational commitment and the relationship between perceived organizational support and affective organizational commitment. Affective commitment is when an individual has a strong desire to remain in the occupation, and it is expected to develop when involvement in the occupation is a satisfying experience for the employee (Meyer et. al., 1993). The lack of divergent validity that was found is likely due to MOHCA being rooted more in affective organizational commitment than originally hypothesized. When an organization has a high score on the MOHCA it would likely create a workplace climate that is more satisfying to the employee, and the employee's 
needs, therefore explaining this stronger relationship between MOHCA and affective organizational commitment.

Focusing on specific facets of climate is done for the purpose of targeting specific outcomes (Carr et. al, 2003). Therefore, given that MOHCA is a measure of the health dimension of workplace climate, it was necessary to examine whether MOHCA was correlated with health-related outcomes. Results of the correlations between MOHCA and job stress, burnout, fatigue and healthy days, provides evidence for the criterion-related validity of the MOHCA scale. This is important because it provides researchers and practitioners with a reason to use the MOHCA scale.

Findings from this study also point to the importance of encouraging workplaces to promote employee health and well-being both at work and outside of work. The incremental validity of MOHCA provides justification for the necessity of a specific climate centered around health, rather than on more general support constructs, when examining health-related outcomes. This is an important consideration for those researchers and organizations concerned with the negative outcomes associated with poor employee health. Because MOHCA was found to be related to health-related outcomes such as burnout, healthy days, job stress and fatigue, its role in the relationship between workplace characteristics and employee health and well-being deserves serious consideration. These results also provide evidence of the social exchange theory framework's predictions as to why MOHCA would be closely related to employee health outcomes. The significant relationships between MOHCA and health 
outcomes is evidence for a reciprocal relationship in which an employee perceives the organization to value the employee's well-being and then is more likely to carry out healthy behaviors in order to benefit the organization. The quality of this relationship is perceived by employees, as exemplified by their MOHCA scores, and was also expected to impact employee health outcomes.

One of the major goals of this study was to demonstrate the need for a construct of health climate separate from the safety climate literature. The purpose of this study was not to argue that safety climate is not important or relevant to employee health issues, but rather to identify the need for a distinct health climate construct to measure this separate component of a healthy organization. Results from this MOHCA scale validation effort indicate that MOHCA and safety climate are indeed distinct constructs that deserve to be measured separately, making it possible for their relationships with other constructs to be examined in greater detail.. This is a notable finding given the previous classification of these constructs together as one in many early and common conceptualizations of the health climate construct. This finding further supports the idea that health climate is misclassified when it is assessed in combination with safety climate.

Additionally, the discriminant validity assessed in Hypothesis 3, which compared the relationship between MOHCA and safety behaviors to the relationship between safety climate and safety behaviors, provides evidence for the present claim that although the two are related, health climate and safety climate do not share the same relationships with outcomes. This finding is 
further supported when examining the incremental validity of the MOHCA. The incremental validity of MOHCA in predicting job stress and "healthy days" above and beyond safety climate provides evidence that safety climate predicts employee health in a more limited scope. While safety climate and employee health were significantly related, the addition of health climate accounted for significantly more variance in employee health outcomes, indicating that safety climate is not sufficient alone in studying employee health outcomes.

The development of MOHCA provides the opportunity for future research to examine the antecedents, outcomes (self-reported or objective) and other relationships that may be associated with this conceptualization of health climate. Additionally, future research might examine the relationship between MOHCA and work related outcomes given the known relationship between work and health. Also, the intraclass correlation (ICC) of .33 in Sample 2 for the MOHCA suggests that it is reasonable to measure this construct at an aggregate group level. This is not an altogether surprising finding given the nature of climate constructs, but is an important point for future research. Future studies can look to examine the relationships surrounding MOHCA with this construct conceptualized at the group level. This would allow for multi-level analyses to be done with the MOHCA to examine this construct in a more realistic way as it occurs in the workplace.

Another major goal in the development present of the MOHCA scale was to create a scale that would translate easily from research to practice. Organizations are increasingly focusing on employee health given the costs 
associated with negative employee health. Some known costs of employee health are a result of absenteeism, reduced productivity, compensation claims, health insurance, and direct medical expenses (Karasek \& Theorell, 1990). This suggests the growing need for a health climate measure that can be translatable into practice. The 9-item MOHCA scale validated in this study is a much more manageable sized scale than an earlier health climate scale, which is useful because it allows organizations to assess many constructs simultaneously along with MOHCA without having to worry too much about survey fatigue being experienced by employees.

In addition to the practical length, the multi-faceted approach in line with organizational levels that was taken in the construction of the MOHCA provides a way for organizations to be able to pinpoint the source of shortcomings in their health climate in order to target interventions to improve employee health and well-being. Workplace interventions can focus on the individual, the organization, or the interaction between the individual and the organization (DeFrank \& Cooper, 1987). A breakdown of the scores on the three factors within the MOHCA (workgroup, supervisor, and organization) can provide a clear indication of where interventions should focus. For example, the upper level management may find that the organizational level of health climate is strong, meaning that they provide resources for health and also facilitate communication, but the employee level of health climate is lacking. This may suggest that health programs and resources may be in place but for various reasons it is not the norm for employees to use them. An organization can use 
this information to plan targeted interventions to create a better overall health climate for its employees.

From a macroergonomics perspective, targeted interventions would promote a sense of feedback control from the employee perspective when they occur following survey administrations, adding to employees' sense of control over their health and positively impacting the interventions. This also suggests, consistent with the macroergonomics principles, that if there are several key functional relationships within the workplace system that contribute to an organization's health climate, a deficiency in any one function could have a large impact on that workplace's health climate due to interactions and interdependencies.

In conclusion, a concise measure of workplace health climate composed of items associated with three levels of the organization was developed and validated in the current study. This measure was developed with the purpose of being readily translatable to practice while still being useful to researchers. The psychometric evidence that was provided in this study demonstrates the viability of the resulting MOHCA scale. Future research efforts can explore the antecedents, outcomes and relationships associated with MOHCA in organizations and its ability to guide interventions to promote employee health. 


\section{References}

American Psychological Association (1999). What is a Psychologically Healthy Workplace? http://www.apahelpcenter.org/articles/article.php?id=34 Arbuckle, J. L. (2006). Amos (Version 7.0) [Computer Program]. Chicago: SPSS. Basen-Engquist, K., Hudmon, K. S., Tripp, M., \& Chamberlain, R. (1998). Worksite Health and Safety Climate: Scale Development and Effect of a Health Promotion Intervention. Preventive Medicine, 27 (1). 111-119.

Bentler, P. M. (1990). Comparative fit indexes in structural models. Psychological Bulletin, 107, 238-246.

Bjerkan, A. M. (2010). Health, environment, safety culture and climate- analyzing the relationships to occupational accidents. Journal of Risk Research, 13(4). 445- 477.

Blau, P. M. (1964). Exchange and power in social life. New York: John Wiley.

Cammann, C., Fichman, M., Jenkins, G., \& Klesh, J. (1983). Assessing the attitudes and perceptions of organizational members. In S.E.

Seashore, E.E. Lawler, III., P.H. Mirvis, \& Cammann, C. (Eds.) Assessing organizational change. A guide to methods, measures, and practices (pp. 71-119). New York: Wiley.

Carr, J. Z., Schmidt, A. M., Ford, J., \& DeShon, R. P. (2003). Climate perceptions matter: A meta-analytic path analysis relating molar climate, cognitive and affective states, and individual level work outcomes. Journal of Applied Psychology, 88(4), 605- 619. 
Cattell, R. B. (1966). The scree test for the number of factors. Multivariate Behavioral Research, 1, 245-267.

CDC - Total Worker Health What Is Total Worker Health? - NIOSH Workplace

Safety and Health Program. (n.d.). Centers for Disease Control and

Prevention. Retrieved July 25, 2012, from

http://www.cdc.gov/niosh/twh/totalhealth.html

Centers for Disease Control and Prevention: Measuring Healthy Days: Population assessment of health-related quality of life. Atlanta Georgia CDC 2000 http://www.cdc.gov/hrqol/.

Chalder, T., Berelowitz, G., Pawlikowska, T., Watts, L., Wessely, S., Wright, D., \& Wallace, E. P. (1993). Development of a fatigue scale. Journal of Psychosomatic Research, $\quad 37(2)$, 147-153.

Clarke, S. (2006). The relationship between safety climate and safety performance: A meta-analytic review. Journal of Occupational Health Psychology, 11(4), 315-327.

Cooper, C. L., \& Cartwright, S. (1994). Healthy mind, healthy organization- A proactive approach to occupational stress. Human Relations, 47, 455-471. Cropanzano, R. \& Mitchell, M. S. (2005). Social Exchange Theory: An Interdisciplinary $\quad$ Review. Journal of Management, 31(6). 874-900. Danna, K. \& Griffin, R. W. (1999). Health and well being in the workplace: A review and synthesis of the literature. Journal of Management, 25, 357-384. DeFrank, R. S., \& Cooper, C. L. (1987). Worksite stress management interventions: Their effectiveness and conceptualization. Journal of 
Managerial Psychology, 2, 4-10.

Demerouti, E., Bakker, A.B., Vardakou, I. \& Kantas, A. (2003). The convergent validity of two burnout instruments: A multitrait-multimethod analysis. European Journal of Psychological Assessment, 19, 12-23.

Eisenberger, R., Huntington, R., Hutchinson, S., \& Sowa, D. (1986). Perceived organizational support. Journal of Applied Psychology, 71, 500-507.

Eisenberger, R., Stinglhamber, F., Vandenberghe, C., Sucharski, I. L., \& Rhoades, L. (2002). Perceived supervisor support: Contributions to perceived organizational support and employee retention. Journal of Applied Psychology, 87(3), 565-573.

Goetzel, R. Z., Hawkins, K., Ozminkowski, R. J., \& Wang, Shaohung (2003). The health and productivity cost burden of the" top 10" physical and mental health conditions affecting six large US employers in 1999. Journal of Occupational and Environmental Medicine, 45(1), 5.

Grawitch, M. J., Gottschalk, M., \& Munz, D. C. (2006). The path to a healthy workplace: A critical review linking healthy workplace practices, employee well-being, and organizational improvements. Consulting Psychology Journal: Practice And $\quad$ Research, 58(3), 129-147.

Grawitch, M. J., Trares, S., \& Kohler, J. M. (2007). Healthy workplace practices and employee outcomes. International Journal Of Stress Management, 14(3), 275- 293. 
Griffin, M. A., \& Neal, A. (2000). Perceptions of safety at work: A framework for linking safety climate to safety performance, knowledge, and motivation. Journal of Occupational Health Psychology, 5(3), 347-358.

Hendrick, H. W. (2002). An Overview of Macroergonomics. In H. W. Hendrick and B. M. Kleiner (Eds.) Macroergonomics: Theory Methods and Applications. (pp. 1-23). Mahwah, NJ: Lawrence Erlbaum Associates, Inc.

Hayes, B. E., Perander, J., Smecko, T., \& Trask, J. (1998). Measuring perceptions of workplace safety: development and validation of the work safety scale. Journal of Safety Research, 29(3), 145-161.

Hinkin, T. R. (1998). A brief tutorial on the development of measures for use in survey questionnaires. Organizational Research Methods, 1, 104-121.

Hobfoll, S. E. (1989). Conservation of resources: A new attempt at conceptualizing stress. American Psychologist, 44(3), 513-524. Hofmann, D. A., \& Morgeson, F. P. (1999). Safety-related behavior as a social exchange: The role of perceived organizational support and leader-member exchange. Journal Of Applied Psychology, 84(2), 286-296.

Hofmann, D.A., Tetrick, L. E. (2003). The etiology of the concept of health: Implications for "organizing" individual and organizational health. In D.A. Hoffmann and L.E. $\quad$ Tetrick (Eds.), Health and Safety in Organizations a Multilevel Perspecitve (pp. 1- 26). San Fracisco, CA: Jossey-Bass.

Hu, L., \& Bentler, P. M. (1995). Evaluating model fit. In R. H. Hoyle (Ed.), Structural equation modeling: Concepts, issues and applications (pp. 76-99). Thousand Oaks, CA: Sage. 
Hu, L., \& Bentler, P. M. (1999). Cutoff criteria for fit indexes in covariance structure analysis: Conventional criteria versus new alternatives. Structural Equation Modeling, 6, 1-55.

Johnson, J. W. (2000). A Heuristic Method for Estimating the Relative Weight of Predictor Variables in Multiple Regression. Multivariate Behavioral Research, 35(1) 1-19.

Jöreskob, K. G., \& Sörbom, D. (1996). LISREL 8.5: User's reference guide. Chicago, IL: Scientific Software International.

Jackson, D. L., Gillaspy, J. A., \& Purc-Stephenson, R. (2009). Reporting practices in confirmatory factor analysis: An overview and some recommendations. Psychological Methods, 14, 6-23.

Kaiser, H. F. (1960). The application of electronic computers to factor analysis. Educational and Psychological Measurement, 20, 141-151.

Karasek, R. A., \& Theorell, T. (1990). Healthy work: Stress, productivity and the reconstruction of working life. New York: John Wiley \& Sons.

Kelloway, E., \& Day, A. L. (2005). Building Healthy Workplaces: What We Know So Far. Canadian Journal Of Behavioural Science/Revue Canadienne Des Sciences Du Comportement, 37(4), 223-235.

Keren, N., Mills, T. R., Freeman, S. A., \& Shelley, M. C. (2009). Can level of safety climate predict level of orientation toward safety in a decision making task? $\quad$ Safety Science, 47, 1312-1323.

Kim, J., \& Mueller, C. W. (1978). Introduction to factor analysis: What it is and how to do it. Beverly Hills, CA: Sage. 
Kline, R. B. (1998). Principles and practice of structural equation modeling. New York, NY: Guilford Press.

Landsbergis, P. A., \& Vivona-Vaughan, E. (1995). Evaluation of an occupational stress intervention in a public agency. Journal of Organizational Behavior, $16,19-48$.

Larkin, T. J., \& Larkin, S. (1996). Reaching and changing frontline employees. Harvard Business Review, 74, 95-104.

Leiter, M. P., Laschinger, H., Day, A., \& Oore, D. (2011). The impact of civility interventions on employee social behavior, distress, and attitudes.

Journal Of Applied Psychology, 96(6), 1258-1274.

Lindstrom, K. (1994). Psychosocial criteria for good work organization.

Scandinavian Journal of Work and Environmental Health, 20, 123-133.

Marsh, H. W., Hau, K., \& Wen, Z. (2004). In search of golden rules: Comment on hypothesis-testing approaches to setting cutoff values for fit indexes and dangers in overgeneralizing Hu and Bentler's (1999) findings. Structural Equation Modeling, 11, 320-341.

Meyer, J. P., Allen, N. J., \& Smith, C. A. (1993). Commitment to organizations and occupations: Extension and test of a three-component conceptualization. Journal Of Applied Psychology, 78(4), 538-551.

Moriarty, D. G., Zack, M. M., \& Kabau R. (2003). The Centers for Disease Control and Preventions's Healthy Days Measures - Population tracking of perceived physical and mental health over time. Health and Quality of Life Outcomes, 37(1). 
Murphy, L.R. (1998). Planned change and organizational health: Figure and groud. In FD. Carver \& T.J. Sergiovvani (Eds.), Organizations and human behavior. (pp. 375-391), New York: McGraw-hill.

Neal, A., Griffin, M. A., \& Hart, P. M. (2000). The impact of organizational climate on safety climate and individual behavior. Safety Science, 34(1-3), 99-109.

Neal, A., \& Griffin, M. A. (2006). A study of the lagged relationships among safety climate, safety motivation, safety behavior, and accidents at the individual and group levels. Journal of Applied Psychology, 91(4), 946-953.

O'Reilly, C. A., \& Chatman, J. (1986). Organizational commitment and psychological attachment: The effects of compliance, identification, and internalization on prosocial behavior. Journal Of Applied Psychology, $71(3), 492-499$.

Rhoades, L., \& Eisenberger, R. (2002). Perceived organizational support: A review of the literature. Journal Of Applied Psychology, 87(4), 698-714.

Ribisl, K. M. \& Reischl, T. M. (1993). Measuring the climate for health at organizations. Development of the worksite health climate scales. Journal of occupational Medicine, 35(8), 812-824.

Samantary, S. K. (2010). Organizational Health A Review of Literature. Social Science International, 26(1), 107-128.

Sauter, S. L., Murphy, L. R., \& Hurrell, J. J. (1990). Prevention of work-related psychological disorders. American Psychologist, 45, 1146-1 158.

Schneider, B. (1975). Organizational Climates: An Essay. Personnel Psychology, 28(4), 447-479. 
Shore, L. M., \& Wayne, S. J. (1993). Commitment and employee behavior:

Comparison of affective commitment and continuance commitment with perceived organizational support. Journal Of Applied Psychology, 78(5), 774780.

Smecko, T., \& Hayes, B. (1999, April). Measuring compliance with safety behaviors at work. Paper presented at the 14th annual conference of the Society for Industrial and Organizational Psychology, Atlanta, GA.

Stanton, J. M., Balzer, W. K., Smith, P. C., Parra, L. F., \& Ironson, G. (2001). A general measure of work stress: The Stress in General scale. Educational and Psychological Measurement, 61, 866-888.

Tabachnick, B. G., \& Fidell, L. S. (1989). Using multivariate statistics (2nd ed.). New York, $\quad$ NY: Harper \& Row.

Tseng, V., \& Seidman, E. (2007). A systems framework for understanding social settings. American Journal of Community Psychology, 39 (3-4), 217-228. Vandenberg, R.J., Park, K., DeJoy, D.M., Wilson, M.G. \& Griffin-Blake, C.S. (2002). The healthy work organization model: Explaning the view of individual health and well being in the workplace. In P.L. Perrewe \& D.C. Ganster (Eds.), Historical and Current Perspectives on Stress and Health. (pp. 57115), Kidlington, UK: Elsevier Science Ltd.

Walsh, B.M., Magley, V.J., Reeves, D. W., Davies-Schrils, K.A., Marmet, M.D. \& Gallus, J.A. (in press). Assessing workgroup norms for civility: The development of the civility norms questionnaire. Journal of Business and Psychology. 
Williams, L., \& Anderson, S. (1991). Job satisfaction and organizational commitment as predictors of organizational citizenship and in-role behaviors. Journal of Management, 17: 601-617.

Wilson, M. G., DeJoy, D. M., Vandenberg, R. J., Richardson, H. A., \& McGrath, A. L. (2004). Work characteristics and employee health and well-being: Test of a model of healthy work organization. Journal Of Occupational \& Organizational Psychology, $\quad 77(4), 565-588$.

Yamada, D. C. (2000). The phenomenon of "workplace bullying" and the need for status- blind hostile work environment protection. Georgetown Law

Journal, 88, 475- 537.

Table 1

Sample Characteristics

\begin{tabular}{lccc}
\hline & Sample 1a & Sample 1b & Sample 2 \\
\hline Average Age & 42 & 43 & $43-51$ \\
& $55 \%$ & $55 \%$ & $70 \%$ \\
Sex & female & female & female \\
Education Level: College & & & \\
degree or higher & $51 \%$ & $46 \%$ & $67 \%$ \\
Ethnicity & $68 \%$ white & $69 \%$ white & $70 \%$ white \\
Job Tenure & $\mathrm{NA}$ & $\mathrm{NA}$ & 9.6 years \\
\hline
\end{tabular}

Note: Sample 2 measured age range rather than actual age.

Samples $1 \mathrm{a}$ and $1 \mathrm{~b}$ have a large number of individuals missing sex and did not measure job tenure. 
Table 2

Health climate item correlations Sample 1

1. In general, employees frequently engage in unhealthy behaviors in my workgroup. ( $r$ )

2. If my health were to decline, my co-workers would take steps to support my recovery.

3. In my workgroup, use of sick days for illness or mental health issues is supported and encouraged.

4. My supervisor sets performance norms that are in conflict with healthy behaviors. ( $r$ )

5. My supervisor encourages participation in organizational programs that promote employee health and well-being.

6. My supervisor encourages health behaviors in my workgroup.

7. My organization is committed to employee health and wellbeing.

8. My organization provides me with opportunities and resources to be healthy.

9. When management learns that something about our work or the workplace is having a bad affect on employee health or well-being, then something is done about it.

10. My organization encourages me to speak up about issues and priorities regarding employee health and well-being.

2

3

4

5

6

7

8

9

10

\begin{tabular}{|c|c|c|c|c|c|c|c|c|c|}
\hline 1 & $.37 * *$ & $.18^{* *}$ & $.22 * *$ & .11 & $.17^{* *}$ & $.26 * *$ & $.24 * *$ & $.27^{* *}$ & $.20 * *$ \\
\hline $.26 * *$ & 1 & $.34 * *$ & $.13^{* *}$ & $.24 * *$ & $.28 * *$ & $.35 * *$ & $.25 * *$ & $.29 * *$ & $.37 * *$ \\
\hline $.24 * *$ & $.34 * *$ & 1 & $.27^{* *}$ & $.43 * *$ & $.46 * *$ & $.49 * *$ & $.43 * *$ & $.39 * *$ & $.50 * *$ \\
\hline $.29 * *$ & $.18 * *$ & $.26 * *$ & 1 & $.38 * *$ & $.48^{* *}$ & $.36 * *$ & $.30 * *$ & $.32 * *$ & $.35 * *$ \\
\hline $.23 * *$ & $.38 * *$ & $.47^{* *}$ & $.13^{* *}$ & 1 & $.77^{* *}$ & $.67 * *$ & $.59 * *$ & $.59 * *$ & $.59 * *$ \\
\hline $.21 * *$ & $.43 * *$ & $.42 * *$ & $.12 * *$ & $.74 * *$ & 1 & $.64 * *$ & $.55^{* *} *$ & $.59 * *$ & $.56 * *$ \\
\hline $.27 * *$ & $.44 * *$ & $.53 * *$ & $.24 * *$ & $.71^{* *}$ & $.69 * *$ & 1 & $.80 * *$ & $.68 * *$ & $.70 * *$ \\
\hline $.22 * *$ & $.36 * *$ & $.46 * *$ & $.17^{* *}$ & $.68 * *$ & $.60 * *$ & $.80 * *$ & 1 & $.61 * *$ & $.61 * *$ \\
\hline $.22 * *$ & $.41 * *$ & $.50 * *$ & $.20 * *$ & $.57 * *$ & $.59 * *$ & $.67 * *$ & $.58^{* *}$ & 1 & $.77 * *$ \\
\hline $.23 * *$ & $.42 * *$ & $.54 * *$ & $.18^{* *}$ & $.67^{* *}$ & $.64^{* *}$ & $.76 * *$ & $.68 * *$ & $.75 * *$ & 1 \\
\hline
\end{tabular}

Note. Results above the diagonal indicate results from sample 2 and numbers below the diagonal indicate results from sample 1 . ( $r$ ) indicates items that were reverse coded. $* *$ indicates $\mathrm{p}<.01$ 
Table 3

Health Climate Items and Factor Loadings by Sample

\begin{tabular}{|c|c|c|c|c|c|c|c|}
\hline \multirow{3}{*}{ Factor } & \multicolumn{6}{|c|}{ Factor Loadings by sample } & \multirow{3}{*}{ Organizatic } \\
\hline & \multirow[t]{2}{*}{$1 a$} & \multicolumn{3}{|c|}{$1 b$} & \multicolumn{2}{|c|}{ 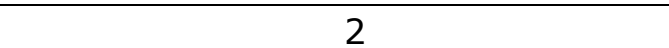 } & \\
\hline & & Workgroup & Supervisor & Organization & Workgroup & Supervisor & \\
\hline Item & & & & & & & \\
\hline $\begin{array}{l}\text { If my health were to decline, my coworkers would } \\
\text { take steps to support my recovery. }\end{array}$ & 0.62 & 0.77 & & & 0.39 & & \\
\hline $\begin{array}{l}\text { In my workgroup, use of sick days for illness or } \\
\text { mental health issues is supported and encouraged. }\end{array}$ & 0.75 & 0.86 & & & 0.57 & & \\
\hline $\begin{array}{l}\text { My supervisor sets performance norms that are in } \\
\text { conflict with healthy behaviors }(r) \text {. }\end{array}$ & 0.32 & & 0.68 & & & 0.45 & \\
\hline $\begin{array}{l}\text { My supervisor encourages participation in } \\
\text { organizational programs that promote employee } \\
\text { health and well-being. }\end{array}$ & 0.83 & & 0.89 & & & 0.78 & \\
\hline $\begin{array}{l}\text { My supervisor encourages health behaviors in my } \\
\text { workgroup. }\end{array}$ & 0.84 & & 0.85 & & & 0.81 & \\
\hline $\begin{array}{l}\text { My organization is committed to employee health and } \\
\text { well-being. }\end{array}$ & 0.91 & & & 0.86 & & & 0.76 \\
\hline $\begin{array}{l}\text { My organization provides me with opportunities and } \\
\text { resources to be healthy. }\end{array}$ & 0.86 & & & 0.91 & & & 0.89 \\
\hline $\begin{array}{l}\text { When management learns that something about our } \\
\text { work or the workplace is having a bad affect on } \\
\text { employee health or well-being, then something is } \\
\text { done about it. } \\
\text { My organization encourages me to speak up about } \\
\text { issues and priorities regarding employee health and } \\
\text { well-being. }\end{array}$ & 0.82 & & & 0.92 & & & 0.80 \\
\hline
\end{tabular}

Note: Data from Sample 1a were analyzed using principal components analysis where only a one-factor solution was found. Samples $1 \mathrm{~b}$ and were analyzed using confirmatory factor analysis. $(r)$ indicates items that were reverse scored. 
Table 4

Factor loadings from first-order to secondorder factor

\begin{tabular}{lrr}
\hline First-order factor & Sample 1b & Sample 2 \\
\hline Workgroup & 0.95 & 0.99 \\
Supervisor & 0.97 & 0.99 \\
Organization & 0.97 & 0.99 \\
\hline
\end{tabular}

Note. Disturbances of these factors were set to be equal 
Table 5

CFA model fit statistics for 9-item Health Climate

$x^{2}$

df $\quad x^{2} / d f$

CFI

SRMR

RMSEA

Sample $1 b$

One-factor model

123.07

27

4.56

0.95

0.12

Hierarchical Three-factor model

88.870

26

3.42

0.97

0.10

Sample 2

One-factor model

199.76

27

7.40

0.85

0.16

Hierarchical Three-factor model

$\begin{array}{llll}179.85 & 26 & 6.92 & 0.88\end{array}$

0.88

0.15

Note: Sample 1b $\mathrm{N}=240$, Sample $2 \mathrm{~N}=244$. Hierarchical three-factor models were run with factor

disturbances set to be equal. 
Table 6

Zero-order Correlations and Descriptive Statistics for Variables in Sample 1

\begin{tabular}{|c|c|c|c|c|c|c|c|c|c|c|c|c|c|}
\hline Variable & $M$ & SD & 1 & 2 & 3 & 4 & 5 & 6 & 7 & 8 & 9 & 10 & 11 \\
\hline 1. Overall MOHCA & 4.7 & 1.25 & $(.89)$ & & & & & & & & & & \\
\hline 2. Workgroup & 4.74 & 1.4 & $.78 * *$ & $(.54)$ & & & & & & & & & \\
\hline 3. Supervisor & 4.73 & 1.23 & $.88^{* *}$ & $.58 * *$ & $(.60)$ & & & & & & & & \\
\hline 4. Organization & 4.67 & 1.53 & $.95 * *$ & $.624 * *$ & $.76 * *$ & $(.91)$ & & & & & & & \\
\hline \multicolumn{14}{|l|}{$\begin{array}{l}\text { 5. Perceived } \\
\text { Suppervisor }\end{array}$} \\
\hline Support & 4.95 & 1.5 & $.58 * *$ & $.47 * *$ & $.53 * *$ & $.52 * *$ & $(.89)$ & & & & & & \\
\hline 6. Civility norms & 5.12 & 1.42 & $.52 * *$ & $.43 * *$ & $.45 * *$ & $.49 * *$ & $.45^{* *}$ & $(.88)$ & & & & & \\
\hline $\begin{array}{l}\text { 7. Safety Climate } \\
\text { 8. Safety }\end{array}$ & 5.23 & 1.3 & $.66 * *$ & $.46^{* *}$ & $.59 * *$ & $.65^{* *}$ & $.62 * *$ & $.49 * *$ & $(.94)$ & & & & \\
\hline Behaviors & 6.03 & 0.95 & $.29 * *$ & $.24 * *$ & $.24 * *$ & $.29 * *$ & $.20 * *$ & $.26 * *$ & $.41^{* *}$ & $(.93)$ & & & \\
\hline 9. Healthy Days & 23.28 & 7.99 & $.20 * *$ & $.14 * *$ & $.13 * *$ & $.22 * *$ & .07 & .06 & $.09 * *$ & .06 & NA & & \\
\hline 10. Job Stress & 1.67 & 1.14 & $-.25 * *$ & $-.20 * *$ & $-.24 * *$ & $-.23 * *$ & $-.23 * *$ & $-.26 * *$ & $-.22 * *$ & -.08 & -.07 & $(.84)$ & \\
\hline 11. Fatigue & 2.85 & 0.86 & $-.28 * *$ & $-.23 * *$ & $-.19 * *$ & $-.28 * *$ & $-.17 * *$ & $-.13 * *$ & -.14 & -.06 & $-.47 * *$ & $.13 * *$ & $(.84)$ \\
\hline
\end{tabular}

Note. Coefficient alphas are in parentheses along the diagonal. $N=530 . * p<.05 . * * p<.01$. 
Table 7

Zero-order Correlations and Descriptive Statistics for Variables in Sample 2

\begin{tabular}{|c|c|c|c|c|c|c|c|c|c|c|c|c|c|}
\hline Variable & $M$ & SD & 1 & 2 & 3 & 4 & 5 & 6 & 7 & 8 & 9 & 10 & 11 \\
\hline 1. Overall MOHCA & 3.66 & 1.28 & $(.89)$ & & & & & & & & & & \\
\hline 2. Workgroup & 4.12 & 1.41 & $.70 * *$ & $(.50)$ & & & & & & & & & \\
\hline 3. Supervisor & 3.75 & 1.40 & $.92 * *$ & $.50 * *$ & $(.71)$ & & & & & & & & \\
\hline 4. Organization & 3.35 & 1.48 & $.95^{* *}$ & $.53 * *$ & $.83 * *$ & $(.88)$ & & & & & & & \\
\hline $\begin{array}{l}\text { 5. Perceived } \\
\text { Organizational }\end{array}$ & 288 & 158 & $67 * *$ & $38 * *$ & $6 \cap * *$ & $7 \cap * *$ & $(06)$ & & & & & & \\
\hline $\begin{array}{l}\text { Support } \\
\text { 6. Workgroup }\end{array}$ & 2.88 & 1.58 & $.6 / x *$ & $.38^{* *}$ & $.60 * \pi$ & $. / 0 \times x$ & $(.96)$ & & & & & & \\
\hline Cohesion & 4.83 & 1.53 & $.45^{* *}$ & $.53 * *$ & $.34 * *$ & $.37 * *$ & $.29 * *$ & $(.92)$ & & & & & \\
\hline $\begin{array}{l}\text { 7. Organizational } \\
\text { Citizenship }\end{array}$ & & & & & & & & & & & & & \\
\hline Behaviors & 6.02 & .89 & $.23 * *$ & $.24 * *$ & $.20 * *$ & $.20 * *$ & $.21 * *$ & $.23 * *$ & $(.90)$ & & & & \\
\hline $\begin{array}{l}\text { 8. Civility Norms } \\
\text { 9. Affective }\end{array}$ & 4.09 & 1.50 & $.58^{* *}$ & $.50 * *$ & $.49 * *$ & $.54 * *$ & $.41 * *$ & $.65^{* *}$ & $.20 * *$ & $(.74)$ & & & \\
\hline Commitment & 3.05 & 1.63 & $.66 * *$ & $.43^{* *}$ & $.56 * *$ & $.67 * *$ & $.73 * *$ & $.34 * *$ & $.21 * *$ & $.43 * *$ & $(.92)$ & & \\
\hline 10. Job Stress & 1.21 & .65 & $-.45 * *$ & $-.39 * *$ & $-.40 * *$ & $-.40 * *$ & $-.33 * *$ & $-.33 * *$ & $-.14 * *$ & $-.37 * *$ & $-.37 * *$ & $(.85)$ & \\
\hline 11. Burnout & 4.52 & 1.29 & $-.41 * *$ & $-.38 * *$ & $-.38 * *$ & $-.36 * *$ & $-.37 * *$ & $-.33 * *$ & $-.36 * *$ & $-.29 * *$ & $-.48 * *$ & $-.41 * *$ & $(.67)$ \\
\hline
\end{tabular}

Note. Coefficient alphas are in parentheses along the diagonal. $\mathrm{N}=530 . * \mathrm{p}<.05 . * * \mathrm{p}<.01$. 
Table 8

Incremental Contributions of Health Climate in Predicting Health-Related outcomes Sample 1

\begin{tabular}{|c|c|c|c|c|c|c|}
\hline \multirow[b]{2}{*}{ Variable } & \multicolumn{2}{|c|}{ Job Stress } & \multicolumn{2}{|c|}{ Fatigue } & \multicolumn{2}{|c|}{ Healthy Days } \\
\hline & $\square$ & $\square R^{2}$ & $\square$ & $\square R^{2}$ & $\square$ & $\square R^{2}$ \\
\hline Model 1 & & $5.2 \%$ & & $3.1 \%$ & & $0.6 \%$ \\
\hline Perceived Supervisor Support & $-0.23 * * *$ & & -0.17 & & 0.08 & \\
\hline Model 2 & & $1.9 \%$ & & $5 \%$ & & $4.5 \%$ \\
\hline Perceived Supervisor Support & $-0.13 *$ & & -0.0 & & -0.07 & \\
\hline MOHCA & $-0.17 *$ & & -0.27 & & $.26 * * *$ & \\
\hline Total $R^{2}$ & & & & & & \\
\hline
\end{tabular}

Note. Hypotheses 7a, 7c and 8. $\mathrm{N}=482$. Standardized coefficients reported. $* \mathrm{p}<.05 . * * \mathrm{p}<.01 . * * * \mathrm{p}<.001$. 
Table 9

Incremental Contributions of overall MOHCA in Predicting Health-related outcomes Sample 2

Variable

Model 1

Workgroup Cohesion

Perceived Organizational Support

Model 2

Workgroup Cohesion

Perceived Organizational Support MOHCA

Total $R^{2}$

\begin{tabular}{|cc|cc}
\multicolumn{2}{|c|}{ Job Stress } & \multicolumn{2}{c}{ Burnout } \\
$\square$ & $\square R^{2}$ & $\square$ & $\square R^{2}$ \\
$-0.26 * * *$ & $16.9 \% \%$ & \multicolumn{2}{c}{$19.1 \%$} \\
$-0.25 * * *$ & & $-0.25 * * *$ & \\
& & $-0.29 * * *$ \\
$-0.16 *$ & $6.1 \% \%$ & & $2.5 \%$ \\
-0.04 & $-0.19 * *$ \\
$-0.36 * * *$ & $-0.16 *$ \\
\multicolumn{2}{|c}{$22 \%$} & $-0.23^{* *}$ \\
\hline
\end{tabular}

Note. Hypotheses $7 a$ and $7 b$. Standardized coefficients reported. $* p<.05 . * * p<.01 . * * * p$ $<.001$. 
Table 10

Incremental Contributions of Health Climate in Predicting Health-related outcomes Sample 1

\begin{tabular}{|c|c|c|c|}
\hline \multirow[b]{2}{*}{ Variable } & Job Stress & \multicolumn{2}{|c|}{ Healthy Days } \\
\hline & $\square \quad \square R^{2}$ & $\square$ & $\square R^{2}$ \\
\hline Model 1 & $4.7 \%$ & & $1.0 \%$ \\
\hline Safety Climate & $-0.22 * * *$ & $0.1^{*}$ & \\
\hline Model 2 & $1.8 \%$ & & $4.0 \%$ \\
\hline Safety Climate & -0.10 & -0.08 & \\
\hline Health Climate & $-0.17^{*}$ & $.26 * * *$ & \\
\hline Total $R^{2}$ & $6.00 \%$ & & \\
\hline
\end{tabular}


Figure 1

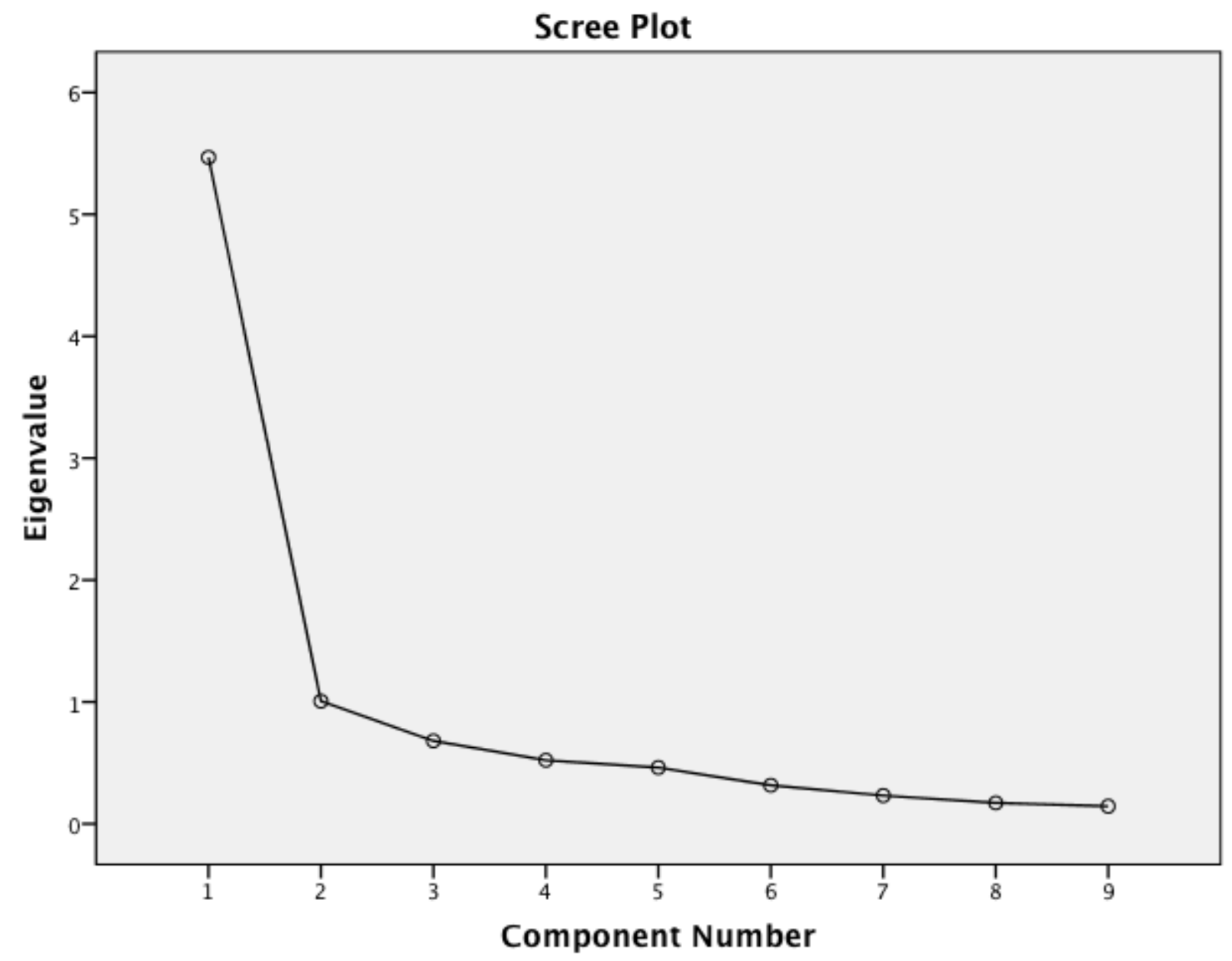


